\title{
Ambulatory electrocardiographic ST segment changes in healthy volunteers
}

\author{
ARSHED A QUYYUMI, CHRISTINE WRIGHT, KIM FOX \\ From the National Heart Hospital, London
}

SUMMARY Twenty four hour ambulatory monitoring was performed on 120 healthy volunteers using a frequency modulated recorder: 50 men and 50 women below 40 years and 20 men between 40 and 60 years were studied. Twenty eight subjects had episodes of ST segment elevation (range 1-3 $\mathrm{mm}$ ), which occurred almost invariably at night with a slow heart rate $(62 \cdot 4 \pm 10 \cdot 4$ beats $/ \mathrm{min})$. ST segment elevation occurred most often in men, and was not found in subjects over the age of 37. Also in 10 subjects horizontal or downsloping ST segment depression (range 1-2 mm) was recorded, usually in association with tachycardia $(135 \pm 10.5 \mathrm{beats} / \mathrm{min})$. Nine of these exercised on a bicycle ergometer, and widespread ST segment depression was observed in eight. Thus ST segment changes, which are often interpreted as myocardial ischaemia in patients with ischaemic heart disease, are commonly seen in $\mathbf{2 4}$ hour electrocardiographic monitoring of healthy volunteers.

Both ST segment elevation ${ }^{12}$ and depression ${ }^{3-5}$ recorded during ambulatory electrocardiographic monitoring have been accepted as indicators of cardiac ischaemia in patients with suspected or diagnosed coronary artery disease. Occasionally ST segment displacement has been noted in individuals who were investigated for chest pain and found to have normal coronary arteries. ${ }^{16-8}$ The frequency, magnitude, and morphology of such changes recorded during 24 hour ambulatory monitoring in normal individuals, however, have not been fully evaluated. Such an assessment is clearly important if ambulatory monitoring is to be used in the diagnosis and evaluation of patients with chest pain. We have determined the types of ST segment changes occurring during 24 hour ambulatory electrocardiographic monitoring during normal daily activity in a group of healthy normal volunteers.

\section{Patients and methods}

Twenty four hour ambulatory monitoring was performed, on 120 volunteers, most of whom were hospital staff or medical students and who were all free from any past or present cardiovascular symptoms. One hundred subjects, 50 men and 50 women, were aged between 20 and 40 years (mean $27.8 \pm 4.8$ ) and 20 men were aged between 40 and 60 years (mean 51.3).

This work was supported by a grant from the British Heart Foundation.

Accepted for publication 12 July 1983

\section{AMBULATORY ELECTROCARDIOGRAPHIC MONITORING}

Two pairs of bipolar electrodes were applied precordially to obtain a two channel recording. One channel recorded the lead CM5 with the indifferent electrode on the manubrium and the exploring electrode in the precordial V5 position. The other channel recorded lead CM2 with the indifferent electrode on the left sternoclavicular joint and the exploring electrode in the precordial V2 position. A ground electrode was placed over the lower right ribs. The skin was initially abraided with electrode jelly (Camjel) and gauze until a sufficiently low skin impedance reading was obtained with an Oxford X1-1 electrode impedance tester. Electrodes (Red-Dot 3M) were applied to the above positions, and monitor leads were secured to the electrodes with adhesive tape to prevent displacement. A magnetic tape was calibrated with a $1 \mathrm{mV}$ signal. Twenty four hour, two channel ambulatory recording of the electrocardiogram was performed using a frequency modulated recorder (Oxford Medilog 2, frequency response $0.05-40 \mathrm{~Hz}) .{ }^{9}$ The monitor tapes were subsequently analysed visually (Oxford Medilog MA20 scanner), and areas of interest were printed out at $25 \mathrm{~mm} / \mathrm{s}$.

Significant ST segment depression was defined as planar or downsloping shift of the ST segment of $1 \mathrm{~mm}$ or more occurring $0.08 \mathrm{~s}$ after the end of the QRS complex. Significant ST segment elevation was defined as an upward shift of the ST segment of $1 \mathrm{~mm}$ 
or more at the J point compared with the resting electrocardiogram. The duration of these ST segment abnormalities was at least $30 \mathrm{~s}$. Abnormalities in the ST segments were analysed and agreed by two observers.

\section{EFFECTS OF POSTURE AND RESPIRATION}

Recordings were obtained for at least $30 \mathrm{~s}$ in various positions, including standing, sitting, and lying supine, prone, and on either side, in 15 subjects who developed ST segment changes during ambulatory monitoring. Also these subjects hyperventilated for about $30 \mathrm{~s}$ until they felt light headed.

\section{EXERCISE TESTING}

Nine subjects who had significant ST segment depression during ambulatory monitoring exercised on a bicycle ergometer with stepwise increases in work load to achieve their age related maximum heart rate response. ${ }^{10}$ A 13 lead electrocardiogram was recorded, which included the conventional 12 lead electrocardiogram and a bipolar lead, CM5, with the leads in positions identical to the first channel of the ambulatory recording.

\section{STATISTICAL ANALYSIS}

Data for the various subgroups are presented as mean \pm standard deviation. Discrete data were analysed using the $\chi^{2}$ test.

\section{Results}

\section{ST SEGMENT DEPRESSION}

Ten subjects, six men and four women between the ages of 22 and 47 years (mean $31.7 \pm 8.6$ ) had episodes of significant planar or downsloping ST segment depression during the 24 hours (Fig. 1). Five subjects were below 30 years, three were between 30 and 40 years, and two were between 40 and 50 years. In lead CM5 the ST segment depression was 1-2 $\mathrm{mm}$ and simultaneously in lead CM2 there was either no change or a smaller magnitude $(0.5-1.0 \mathrm{~mm})$ depression of the ST segment.

The mean heart rate at the onset of ST segment depression was $135 \pm 19.5$ beats $/ \mathrm{min}$, ranging from 100 to $180 \mathrm{beats} / \mathrm{min}$. The number of episodes varied from one to five during the 24 hours, and the mean duration of the episodes was $20.4 \pm 27.8 \mathrm{~min}$. None of these subjects suffered any symptoms during these periods. No ST segment depression occurred at night.

In eight of these subjects electrocardiograms were recorded in various positions and during hyperventilation. No appreciable ST segment changes were observed. T wave changes alone were often found, which were related to posture and respiration.
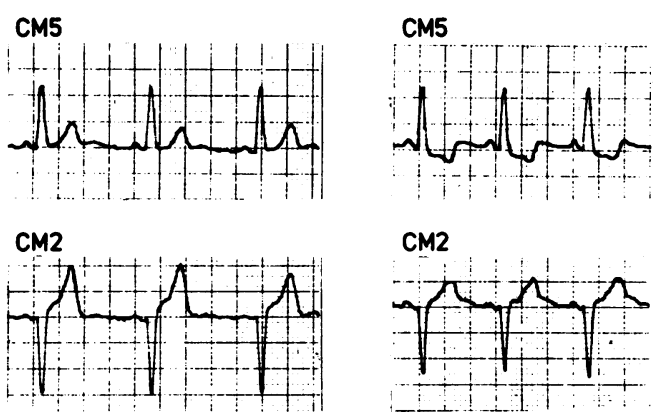

Baseline

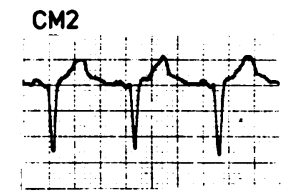

During ST segment depression

Fig. 1 ST segment depression in a 28 year old man. Recordings from leads CM5 and CM2 obtained before (left) and during (right) ST segment depression.

\section{ST SEGMENT ELEVATION}

Twenty eight subjects, 22 men and six women $(p<0.01)$, had episodes of significant ST segment elevation during ambulatory monitoring. Twenty one of the 28 subjects were under 30 years, seven were between 30 and 40 years, and none of the volunteers above 40 years had ST segment elevation $(p<0.01)$.

The magnitude of the ST segment elevation varied from 1 to $3.0 \mathrm{~mm}$ above the baseline in lead CM5 (Table). ST segment elevation almost invariably occurred during sleep. The mean heart rate at the onset of ST segment elevation was $62.4 \pm 10.4$ beats/ $\mathrm{min}$, and there were no appreciable changes in the heart rate at the onset or end of the episodes of ST segment elevation (Fig. 2). Most individuals (23 out of 28) had gradually increasing ST segment elevation which lasted for several hours (mean 3 hours $14 \mathrm{~min}$ ) during sleep (Fig. 3), and 19 of them had superimposed briefer episodes of further discrete ST segment elevation. Five of the 28 subjects had discrete brief episodes of ST segment elevation only (Fig. 2), with a mean duration of $36.6 \pm 31.9 \mathrm{~min}$.

Seventeen subjects had ST segment changes in lead

Table Number of episodes and characteristics of ST segment elevation in normal volunteers

\begin{tabular}{lllll}
\hline \multicolumn{5}{c}{$S T$ segment elevation } \\
\cline { 2 - 5 } & $1 \mathrm{~mm}$ & $1.5 \mathrm{~mm}$ & $2.0 \mathrm{~mm}$ & $2.5-3.0 \mathrm{~mm}$ \\
\hline $\begin{array}{c}\text { No of } \\
\text { episodes }\end{array}$ & 30 & 19 & 19 & 3 \\
$\begin{array}{c}\text { Heart rate } \\
\text { at onset } \\
\text { (beats/min) }\end{array}$ & $65 \cdot 7 \pm 12.3$ & $59.7 \pm 9.9$ & $57.8 \pm 7.5$ & $61 \pm 16.7$ \\
$\begin{array}{c}\text { Mean } \\
\text { duration of } \\
\text { episodes } \\
\text { (min) }\end{array}$ & $194 \pm 160$ & $69 \pm 70$ & $82 \pm 100$ & $53 \pm 52$ \\
\hline
\end{tabular}




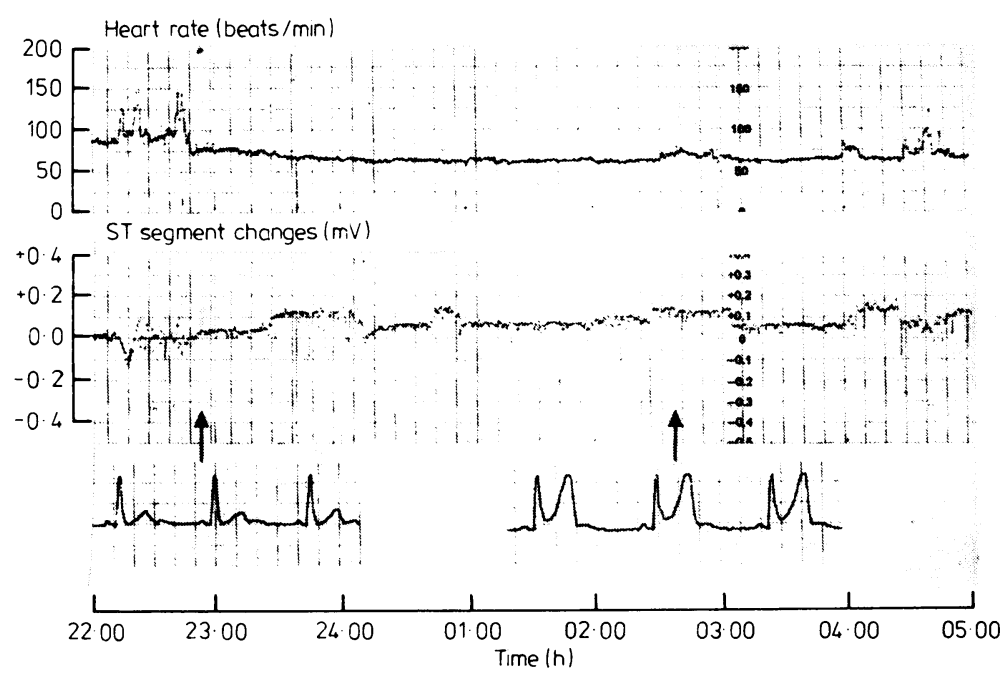

Fig. 2 Heart rate and ST segment changes during the night in a 27 year old subject with episodes of ST segment elevation. Recordings from lead CM 5 before (left) and during (right) ST segment elevation.

CM2 at the same time as ST segment elevation in lead CM5. Six subjects had ST segment elevation of 0.5$1.5 \mathrm{~mm}$, a change always smaller than that in lead CM5, whereas 11 subjects had depression of the ST segment of $0.05-1.0 \mathrm{~mm}$ in lead CM2. The other 11 subjects had no ST segment changes in lead CM2 when there was elevation in lead CM5.

In all these subjects the $T$ wave became upright and peaked in lead CM5 during ST segment elevation (Fig. 2), whereas in lead CM 2 the $\mathrm{T}$ wave amplitude was either the same or reduced.

In 10 of the 28 subjects these ST segment changes could not be reproduced by posture or respiration.

EXERCISE TESTING

Nine of the 10 subjects with ST segment depression during ambulatory monitoring were exercised on the bicycle ergometer. During tachycardia, eight subjects developed significant ST segment depression, often in several leads. At no time did any of these subjects complain of symptoms of cardiac ischaemia.

\section{Discussion}

Several studies of patients with chest pain have determined the incidence of ST segment depression and compared it with results of coronary arteriography. ${ }^{6-8} \mathrm{~A}$ few important findings have emerged. Firstly, a number of patients with angiographically proved coronary artery disease had ST segment depression on ambulatory monitoring; a smaller but substantial group without occlusive coro-
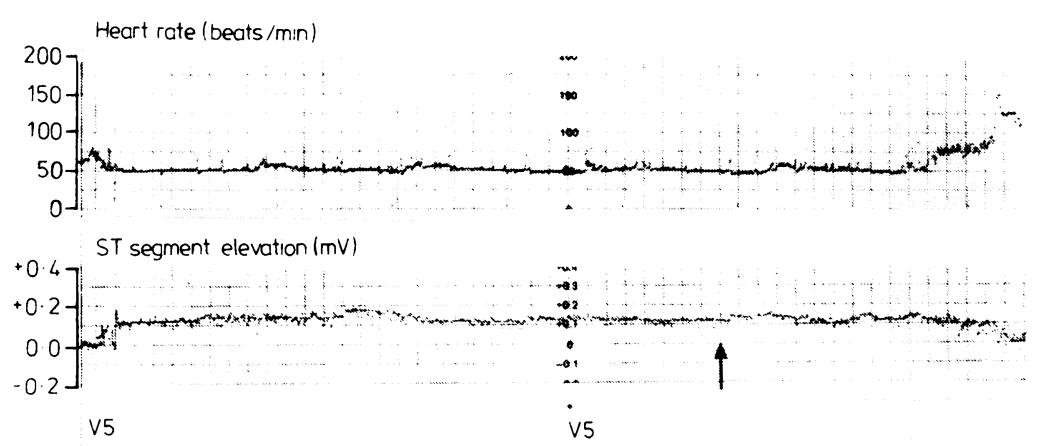

Fig. 3 Trend of heart rate and $S T$ segment changes in a 32 year old man with gradual elevation of the ST segment during the night. Recordings from lead CM5 before (left) and during (right) $S T$ segment elevation.

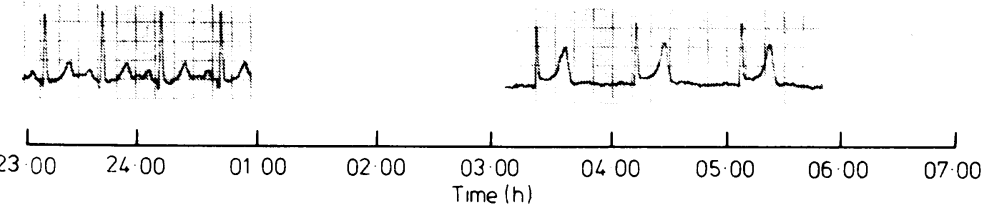


nary artery disease, however, also showed similar changes. Secondly, these studies showed that most of the episodes of ST segment depression were not associated with pain, although they resembled changes occurring during chest pain and it was assumed that they, nevertheless, reflected myocardial ischaemia.

Only a few studies in normal subjects have determined the true incidence of ST segment changes on ambulatory monitoring. Stern and Tzivoni ${ }^{11}$ found no evidence of ST segment change in $\mathbf{4 2}$ normal subjects, but these recordings were conducted only at night. A study by Armstrong et al. ${ }^{12}$ in 50 asymptomatic men aged 35 to 49 found transient ST segment depression in 15. The higher incidence of ST segment depression in this study may be due to several factors. The average age of their subjects was such that silent ischaemia could not be excluded, and only 35 subjects were tested for orthostatic ST segment changes; four individuals who developed such changes were also included in the analysis.

Our study has shown that both ST segment depression and ST segment elevation often occur in normal volunteers. In none of the subjects who were tested could these changes have been induced by posture or hyperventilation. ST segment depression occurred only when there was a tachycardia, and almost all of these subjects developed ST segment depression during an exercise test. Although typical planar or downsloping ST segment changes were observed, they never exceeded $2 \mathrm{~mm}$.

ST segment elevation occurred in almost a quarter of the subjects. It did, however, have an easily recognisable pattern. In all subjects ST segment elevation occurred at low heart rates and almost invariably at night. Some subjects had distinct transient episodes of 2-3 mm elevation lasting a few minutes, but most had a more gradual change over several hours. Finally, no normal person over the age of 37 had ST segment elevation, and the incidence was highest in the youngest subjects. It is clearly important to be aware of these findings, otherwise coronary spasm may be inappropriately diagnosed in young subjects in whom ambulatory monitoring is being used to evaluate atypical chest pain.

The cause of these ST segment changes is unclear. False positive ST segment changes can occur during exercise testing,,$^{1314}$ and therefore it is not surprising to find such changes in ambulatory monitoring. One of the difficulties with studies using normal volunteers, however, is excluding the possibility of latent disease. In an attempt to overcome this we not only studied subjects in the age group in which coronary disease usually occurs but also investigated a large number of young people in whom the likelihood of coronary disease would be low. Subjects who developed episodes of ST segment depression were all asymptomatic, normotensive, whites who were not having any treatment. Physical examination and resting electrocardiograms were normal. Furthermore, these changes on the ST segment could not be induced by posture or respiration.

ST segment monitoring has been widely used for evaluating patients with chest pain, ${ }^{3-6}$ and several workers have also used this technique to evaluate drug treatments ${ }^{15-17}$ in ischaemic heart disease. Although ambulatory monitoring may be extremely useful in both circumstances, it is important to be aware of the normal response if meaningful data are to be obtained.

One of the essential prerequisites of using ambulatory electrocardiographic systems for diagnosing myocardial ischaemia is to ensure that the composite system " can accurately reproduce ST segment changes. ${ }^{9}$ The frequency response of the ST segment during electrocardiographic recording is at the lower frequency range of $0.05-0.5 \mathrm{~Hz}$. Several of the older ambulatory monitoring studies were hampered by the use of direct recording systems which did not have an adequate response at these low frequencies and consequently produced severe distortions in the ST segments. ${ }^{18-20}$ The magnetic tape, frequency modulated recorder, scanner, and print out systems used in this study have an adequate low frequency response, down to $0.05 \mathrm{~Hz}$ (3 dB down), 9 and this was tested regularly. We took precautions to minimise baseline drift of the electrocardiogram by adequate skin preparation and electrode adherence.

In conclusion, this study in healthy volunteers shows the frequent occurrence of ST segment changes during ambulatory monitoring. ST segment depression occurred with a tachycardia and could usually be reproduced during conventional exercise testing. ST segment elevation, with peaked $T$ waves, occurred significantly more often in young men and occurred almost invariably at night. $T$ wave changes were commonly observed and were often due to orthostatic changes:

\section{References}

1 Golding B, Wolf E, Tzivoni D, Stern S. Transient S-T elevation detected by 24-hour ECG monitoring during normal daily activity. Am Heart $\mathcal{F}$ 1973; 86: 501-7.

2 Biagini A, Mazzei MG, Carpeggiani C. Vasospastic ischemic mechanism of frequent asymptomatic transient ST-T changes during continuous electrocardiographic monitoring in selected unstable angina patients. Am Heart f 1982; 103: 13-20.

3 Selwyn AP, Fox K, Eves M, Oakley D, Dargie H, Shillingford J. Myocardial ischaemia in patients with frequent angina pectoris. $\mathrm{Br} \mathrm{Med} \mathcal{F} 1978$; ii: 1594-6. 
4 Allen RD, Gettes LS, Phalan C, Avington MD. Painless ST-segment depression in patients with angina pectoris. Chest 1976; 69: 467-73.

5 Schang SJ Jr, Pepine CJ. Transient asymptomatic S-T segment depression during daily activity. Am $\mathcal{F}$ Cardiol 1977; 39: 396-402.

6 Stern S, Tzivoni D, Stern Z. Diagnostic accuracy of ambulatory ECG monitoring in ischemic heart disease. Circulation 1975; 52: 1045-9.

7 Crawford MH, Mendoza CA, O'Rourke RA, White DH, Boucher CA, Gorwit J. Limitations of continuous ambulatory electrocardiogram monitoring for detecting coronary artery disease. Ann Intern Med 1978; 89: 1-5.

8 Kunkes SH, Pichard A, Meller J, Gorlin R, Herman MV, Kupersmith J. Use of the ambulatory ECG to diagnose coronary artery disease. $\mathcal{F}$ Electrocardiol 1980; 13: 341-6.

9 Bragg-Remschel DA, Anderson CM, Winkle RA. Frequency response characteristics of ambulatory ECG monitoring systems and their implications for ST segment analysis. Am Heart $\mathcal{F}$ 1982; 103: 20-31.

10 Âstrand I. The physical work capacity of workers 50-60 years old. Acta Physiol Scand 1958; 42: 73-86.

11 Stern S, Tzivoni D. Dynamic changes in the ST-T segment during sleep in ischemic heart disease. Am $\mathcal{F}$ Cardiol 1973; 32: 17-20.

12 Armstrong WF, Jordan JW, Morris S, McHenry PL. Prevalence and magnitude of $S-T$ segment and $T$ wave abnormalities in normal men during continuous ambulatory electrocardiography. Am $\mathcal{F}$ Cardiol 1982; 49: $1638-42$.

13 Borer JS, Brensike JF, Redwood DR. Limitations of the electrosardiographic response to exercise in predicting coronary-artery disease. $N$ Engl f Med 1975; 293: 36771.

14 Cumming GR, Dufresne C, Kich L, Samm J. Exercise electrocardiogram patterns in normal women. $\mathrm{Br}$ Heart $\mathcal{f}$ 1973; 35: 1055-61.

15 Winsor T, Berger $\mathrm{HJ}$. Oral nitroglycerin as a prophylactic antianginal drug: clinical, physiologic, and statistical evidence of efficacy based on a three-phase experimental design. Am Heart $\mathcal{F}$ 1975; 90: 611-26.

16 Fox KM, Jonathan A, Selwyn AP. Effects of platelet inhibition on myocardial ischaemia. Lancet 1982; ii: 727-30.

17 Subramanian B, Bowles MJ, Davies AB, Raftery EB. Combined therapy with verapamil and propranolol in chronic stable angina. Am $\mathcal{F}$ Cardiol 1982; 49: 125-32.

18 Hinkle LE Jr, Meyer J, Stevens M, Carver ST. Tape recordings of the ECG of active men. Limitations and advantages of the Holter-Avionics Instruments. Circulation 1967; 36: 752-65.

19 Balasubramanian V, Lahiri A, Green HL, Stott FD, Raftery EB. Ambulatory ST segment monitoring. Problems, pitfalls, solutions and clinical application. Br Heart $\mathcal{f}$ 1980; 44: 419-25.

20 Berson AS, Pipberger HV. The low-frequency response of electrocardiographs, a frequent source of recording errors. Am Heart f 1966; 71: 779-89.

Requests for reprints to Dr Kim Fox, National Heart Hospital, Westmoreland Street, London W1M 8BA. 